\title{
Features of interdisciplinarity of modern pedagogy
}

\section{Características da interdisciplinaridade da pedagogia moderna}

\section{Características de la interdisciplinariedad de la pedagogía moderna}

\author{
Tetiana Kotyk $^{1}$ iD , Svitlana Romanyuk ${ }^{2}$ iD , Maryna Kisil ${ }^{3}$ iD \\ ${ }^{1}$ Vasyl Stefanyk Precarpathian National University, Ivano-Frankivsk, Ukraine. \\ ${ }^{2}$ Yuriy Fedkovych Chernivtsi National University, Chernivtsi, Ukraine. \\ ${ }^{3}$ Kharkiv State Academy of Design and Arts, Kharkiv, Ukraine. \\ Corresponding author: \\ Tetiana Kotyk \\ Email: medynska_teti@ukr.net \\ How to cite: Kotyk, T., Romanyuk, S., \& Kisil, I-F. (2022). Features of interdisciplinarity of modern pedagogy. Revista \\ Tempos e Espaços em Educação, 15(34), e16936. http://dx.doi.org/10.20952/revtee.v15i34.16936
}

\begin{abstract}
The most important task of modern education is the formation of a highly developed personality capable of effectively assimilating knowledge, making non-standard decisions and thinking creatively. Modernization of the content of education, renewal of teaching methods and means are the basis of new pedagogical searches. The study of the problem of interdisciplinarity is important for the development of scientific, theoretical foundations of pedagogy, as well as for the practical activities of teachers. Interdisciplinarity will be able to provide a unified methodological basis for the subject system as a whole by highlighting systematizing scientific ideas that facilitate learning in all subjects. Interdisciplinary approaches are in line with the pressing problems of modern education. Since academic subjects are built in the logic of specific sciences, and all of them to one degree or another are related to each other, it becomes necessary to establish interdisciplinarity. Thus, the main purpose of the article is to determine the basic features of the interdisciplinarity of modern pedagogy. The research was carried out using the following theoretical methods: systems analysis and synthesis, induction and deduction, comparison, classification, generalization and systematization, idealization and abstraction.
\end{abstract}

Keywords: Interdisciplinarity. Methods of teaching. Modern pedagogy. Specialists. Student's personality.

\section{RESUMO}

A tarefa mais importante da educação moderna é a formação de uma personalidade altamente desenvolvida, capaz de assimilar conhecimentos de forma eficaz, tomando decisões atípicas e pensando criativamente. A modernização dos conteúdos da educação, a renovação dos métodos e meios de ensino estão na base de novas pesquisas pedagógicas. O estudo do problema da interdisciplinaridade é importante para o desenvolvimento dos fundamentos científicos e teóricos 
da pedagogia, bem como para as atividades práticas dos professores. A interdisciplinaridade poderá fornecer uma base metodológica unificada para o sistema de disciplinas como um todo, destacando ideias científicas sistematizadas que facilitem a aprendizagem em todas as disciplinas. As abordagens interdisciplinares estão de acordo com os problemas prementes da educação moderna. Como as disciplinas acadêmicas são construídas na lógica das ciências específicas, e todas elas, em um grau ou outro, se relacionam entre si, torna-se necessário o estabelecimento da interdisciplinaridade. Assim, o objetivo principal do artigo é determinar as características básicas da interdisciplinaridade da pedagogia moderna. A pesquisa foi realizada utilizando os seguintes métodos teóricos: análise e síntese de sistemas, indução e dedução, comparação, classificação, generalização e sistematização, idealização e abstração.

Palavras-chave: Especialistas. Interdisciplinaridade. Métodos de ensino. Pedagogia moderna. Personalidade do aluno.

\section{RESUMEN}

La tarea más importante de la educación moderna es la formación de una personalidad altamente desarrollada capaz de asimilar conocimientos de manera efectiva, tomar decisiones atípicas y pensar de manera creativa. La modernización de los contenidos de la educación, la renovación de los métodos y medios de enseñanza son la base de nuevas búsquedas pedagógicas. El estudio del problema de la interdisciplinariedad es importante para el desarrollo de los fundamentos científicos y teóricos de la pedagogía, así como para las actividades prácticas de los docentes. La interdisciplinariedad podrá proporcionar una base metodológica unificada para el sistema de asignaturas en su conjunto al resaltar las ideas científicas sistematizadoras que faciliten el aprendizaje en todas las asignaturas. Los enfoques interdisciplinarios están en consonancia con los problemas urgentes de la educación moderna. Dado que las asignaturas académicas se construyen en la lógica de las ciencias específicas, y todas ellas en un grado u otro se relacionan entre sí, se hace necesario establecer la interdisciplinariedad. Por tanto, el objetivo principal del artículo es determinar las características básicas de la interdisciplinariedad de la pedagogía moderna. La investigación se llevó a cabo utilizando los siguientes métodos teóricos: análisis y síntesis de sistemas, inducción y deducción, comparación, clasificación, generalización y sistematización, idealización y abstracción.

Palabras clave: Especialistas. Interdisciplinariedad. Métodos de enseñanza. Pedagogía moderna. Personalidad del alumno.

\section{INTRODUCTION}

The concept of "interdisciplinarity" entered the scientific circulation of use in the second half of the XX century and, "reflecting the change in epistemological guidelines, more than once changed its meaningful direction."

Until recently, domestic scientists used the term "interdisciplinarity", understanding it as borrowing theories and methods of other sciences to solve intradisciplinary problems.

Interdisciplinarity implies the joint work of specialists studying all sorts of aspects of a common (single) problem. Moreover, each of the specialists relies on his own methodological disciplinary base. In such conditions, when defining and solving a specific scientific problem, the disciplinary fields can be revealed, which provides extensive opportunities for the interaction of various disciplines in solving complex problems of the relationship between nature and society.

In foreign scientific literature there are many definitions of the concept of "interdisciplinarity", however, differing from each other. The authors put different content into the same term (Klein, 2002).

Although the concept of "interdisciplinarity" began to be used in the 20th century, the general concept is rooted in the past. Tatiana Augsburg, an associate professor at the University of 
San Francisco, points out in her research that interdisciplinarity dates back to Greek philosophy. Julie Thomson Klein, professor at Wayne University in Detroit (USA), notes that the basis of this concept lies in some ideas spreading through the ideas of generally accepted standard knowledge, synthesis and integration of knowledgegrowing.

Dr. Heidi Hayes Jacobs, President of Curriculum Developers, interprets interdisciplinarity as "a field of knowledge and curriculum approach that deliberately applies the methodology and language of more than one discipline to explore a central topic, issue, problem, event or experience." (Úcar, 2013)

In contrast to traditional views of the body of knowledge of a particular discipline, interdisciplinarity does not emphasize the limitation of knowledge, but concentrates on connections and relationships between different disciplines studying their subject.

Professor Nissani Moti explores the concept of interdisciplinarity by breaking a word into its constituents: the prefix inter (between, in the middle, connecting) and the word disciplinarity (discipline). In his opinion, interdisciplinarity is a combination of two or more disciplines into one whole. Nissan Moti notes that interdisciplinarity tends to occur in the following situations (Rana, 2017):

- interdisciplinary knowledge contains knowledge of two or more disciplines;

- interdisciplinary research combines the components of two or more disciplines in order to find new knowledge;

- interdisciplinary training - combining the components of two or more disciplines in the general program.

The author also draws attention to the fact that the "everyday" understanding has become quite dense: each discipline has its own specialists and is associated with one subject. Such a representation prevents the interpenetration and synthesis of various subject areas.

The lack of a common vocabulary for specialists and researchers in the field of interdisciplinarity introduces certain complications in the scientific community.

In the last years of the XXI century, due to the intensive development of scientific research in the field of interdisciplinarity, the development of pedagogical science will contribute to the introduction of interdisciplinary approaches into the general educational practice of schools and higher educational institutions.

Interdisciplinary approaches address complex and large-scale problems within the same discipline. In pursuit of a common goal, researchers, teachers and students contribute to linking and integrating two or more academic disciplines, professions or technologies with their methods and perspectives.

The adjective "interdisciplinary" is widely used in the educational sphere. Researchers from two or more disciplines combine their approaches and transform them so that students can easily master the subject within a multitude of traditional disciplines in order to solve certain problems in an acceptable way. Interdisciplinarity examines the subject from different angles in a variety of ways, permeating the disciplines and creating a new way of learning about the subject. The common goal of comprehension brings together various methods and confirms the general problem and subject, although they may be extended to other disciplines (Vlieghe, Zamojski, 2020).

So, interdisciplinarity is one of the ways to expand the scientific worldview, which consists in the study of various phenomena outside of one scientific discipline. This is one of the ways in which various specialized scientific practices interact.

A comprehensive study of the problem of interdisciplinarity is important for the development of the scientific and theoretical foundations of pedagogy, the practical activities of teachers.

Interdisciplinarity of pedagogy is a systemic and multidimensional concept. Its varieties are considered as follows: 
- interdisciplinarity itself, interpreted in narrower and broader meanings:

a) an approach that deals with a subject outside the discipline, but its purpose remains within the framework of disciplinary research and is to transfer methods from one discipline to another;

b) an approach that combines the methods of different industries, modifying them or creating a new method for studying a subject that goes beyond the limits of one discipline;

- multidisciplinarity - cooperation is based on the simultaneous or sequential study of a complex problem with the prospects of several areas of knowledge without any mutual assimilation, transformation and coordination of the methodological tools of these disciplines;

- crossdisciplinarity - a method that takes the researcher outside of a particular discipline, but without cooperation (cooperation) or (integration) with the relevant disciplines.

Crossdisciplinarity studies a subject using methods taken from disciplines that are not directly related to the subject. In crossdisciplinary communication, discipline limits are transcended, but neither methods nor goals change, while interdisciplinarity mixes the practices and foundations of all the disciplines involved;

- transdisciplinarity - a term introduced by Jean Piaget in 1970, defines the methodological basis for the application of integrated scientific approaches to such complex problems that go beyond the established academic disciplines: natural environment, energy, health, culture.

An interdisciplinary approach is defined in the reference literature as an approach that practices research using two or more disciplines and leads to a better understanding of them5. Educational science argues that for the productive application of knowledge in the practice of various disciplines, it is important to establish broad connections between them.

Life itself dictates the predominant use of certain means, forms and methods of teaching in the system of continuous professional growth of teaching staff. Each period of the life of society sets before teachers the corresponding goals and methods of their achievement. The modern concept of education is self-development, self-improvement of the individual. This is primarily characteristic of the system of postgraduate pedagogical education, which is directly responsible for ensuring the continuous development of the professional competence of teachers. The purpose of the article is to highlight the conceptual foundations of the essence of interdisciplinary relationships in pedagogical science and lifelong education of teaching staff.

\section{METHODOLOGY}

The main goal of the study is to determine the basic features of the interdisciplinarity of modern pedagogy. For this, a number of methods were applied that make up the research methodology. The research was carried out using the following theoretical methods: systems analysis and synthesis, induction and deduction, comparison, classification, generalization and systematization, idealization and abstraction.

\section{RESULTS AND DISCUSSION}

Interdisciplinarity is of particular importance for the productivity of the use of organizational forms of education, the purposefulness of the transformation of all the main links of the educational process:

- setting the objectives of the lesson;

- development of the content of the lesson;

- organizing the cognitive activity of students;

- use of means of enhancing educational activity (visual aids, technical means);

- analysis of the levels of learning and development;

- integrated lesson and thematic planning. 
The transformation of the links of the educational process, taking into account interdisciplinarity, should be aimed at the formation of an active position of the student in the learning process, providing for the implementation of the unity of the scientific and ideological content of training and the active educational and cognitive activity of students, as well as the unity of the educational, developmental and educational functions of training.

The educational function is that with the help of interdisciplinarity, the teacher forms such qualities of students' knowledge as consistency, depth, awareness, flexibility. The interaction of academic disciplines acts as a means of developing concepts and assimilating the connections between them.

The educational function includes (Florian, Black-Hawkins, 2011):

1) improving the content of education - one of the criteria for the selection and approval of educational material in the curriculum of academic disciplines;

2) the formation of the consistency of students' knowledge based on the development of leading scientific ideas and concepts;

3 ) the formation of polytechnic knowledge and skills.

The developmental function is determined by the role of interdisciplinarity in the development of the systemic and creative thinking of students, in the formation of their cognitive activity, independence and interest in knowledge. The connection between various academic disciplines contributes to the comprehension of the subject inertia of thinking and broadening the horizons of students.

The upbringing function is expressed in the promotion of interdisciplinary synthesis in all areas of the education of schoolchildren in teaching. Using the interconnection of subjects, the teacher implements an integrated approach to education, increases the ideological, educational and polytechnic orientation of teaching (Suissa, 2015).

The educational function of interdisciplinarity includes the formation of a worldview, labor education, and vocational guidance.

One of the most important functions of interdisciplinarity in school is the formation of students' moral and aesthetic ideals.

Integration and coordination of the content of academic subjects lays a solid foundation for a scientific understanding of the world. Broad philosophical generalizations - the material unity and cognizability of the world, the laws of development and the relationship between natural and social phenomena - are based on the fundamental laws of natural science and social science. Therefore, the formation of a worldview is based on the implementation of especially important connections between cycles of objects (Bansak, Starr, 2021) .

Interdisciplinary generalizations are one of the factors for optimizing the teaching process, increasing its effectiveness, and eliminating the overload of teachers and students.

Interdisciplinary generalizations contribute to the creation of the basis of a single methodological essence of an integral subject system, where the cited systematized scientific ideas that permeate teaching in all subjects are brought to the fore. Interdisciplinary generalizations in a logically complete form represent a conscious relationship between the elements of the structure of various academic subjects, expressed in a single form. Interdisciplinary generalizations are not only a means of all-round development of a student's personality, but also one of the ways of forming certain pedagogical tasks, creating a general subject system of knowledge, skills, and relationships (Yuk, Fai Leung.2003).

The origins of interdisciplinary generalizations in classical pedagogy are associated with the search for methods of reflecting the integrity of nature in the content of educational material, which contributes to the emergence of the idea of subject synthesis.

Thus, interdisciplinary generalizations are a pedagogical category for designating synthesizing, integrative relations between objects, phenomena and processes of reality, which are 
reflected in the content, forms and methods of the educational process and perform educational, developmental and upbringing functions in their limited unity.

Interdisciplinary generalizations should, naturally, be included in the presentation of the teacher's educational material, not duplicating, but developing the basic knowledge of students. The possibility of implementing interdisciplinary generalizations can be different and depends on the content of the lesson (Table 1).

Table 1. Levels of implementation of interdisciplinarity in pedagogical practice.

Level of implementation of interdisciplinarity in pedagogical practice

Primitive level

Fragmentary level

The highest level
The essence of the level

The most primitive level of the use of interdisciplinarity is expressed in a general integrated approach to the formulation and solution of educational tasks.

Interdisciplinarity is used in the construction of educational material in the form of examples, comparisons, general facts, views, beliefs and makes up a fragment in the structure of the lesson.

The highest level presupposes the organic inclusion in the structure of the lesson of educational material from other academic disciplines, without which the new material of the program cannot be well studied, requiring generalization, synthesis of knowledge. At this level, generalizing lessons are held, where knowledge from various subjects is combined from the position of common worldview ideas.

Moving from one level to another is associated with an increase in the activity of teachers and the independence of students in operating with interdisciplinary generalizations, with an increase in its intensity in the educational process, with an increase in the effectiveness of the functions of education, development and upbringing in their unity. The availability of learning based on interdisciplinarity is ensured by the very organization of the learning process, which includes generalized intersubject elements in the content of educational and cognitive activities and contributes to the formation of generalized skills in students' use.

In the mass experience of schools, lessons prevail only with the use of elements of interdisciplinary synthesis, which is explained both by the specifics of the content of the programs and the inability of teachers to make connections between different subjects. At the first stage of general secondary education, interdisciplinarity based on the above three levels is the most acceptable and is used in teaching practice.

Pedagogy does not belong to closed, purely branch disciplines, it develops in all multidimensional connections with other branches of scientific knowledge. The scope of its functioning is practically unlimited, as pedagogical science affects the effectiveness of not only all spheres of society, but also the formation of the personality of each citizen, his level of education, upbringing, values, translation of social and cultural experience between generations, development of intellectual potential of each country, the quality of its human resources in general.

At the same time, the development of modern pedagogy is increasingly based on research that goes beyond disciplinary and acquires the characteristics of interdisciplinary and sometimes multidisciplinary research. This situation, in order to reach a qualitatively new level of research in the field of education in accordance with the complex, rapidly changing realities of the globalized world, necessitates either expanding the subject of pedagogy or defining the subject field of education. The problem of expanding the subject of pedagogy, overcoming the methodological 
multidimensionality in pedagogical research, Polish scientists solve with the help of subdisciplines of pedagogy, the range of which is constantly expanding (Smelser, 2004).

Pedagogy includes a large number of subdisciplines, including the history of education, philosophy of pedagogy, pedagogy of religion, pedagogy of culture, social pedagogy, pedagogy of resocialization, pedagogy of care, prenatal pedagogy, family pedagogy, pedagogy of creativity, inclusive pedagogy, sports pedagogy, sociology of education, education, basics of educational law, economics of education, gender pedagogy, theory of education, alternative pedagogy, early school pedagogy, management pedagogy, comparative pedagogy, media pedagogy, special pedagogy, health pedagogy, labor pedagogy, pedagogy, school didactics, learning psychology, general pedagogy, methods of pedagogical research (Phoenix et al,2013)

At the same time, such an expansion of the subject field of pedagogical science is not able to stop scientific discussions among Polish scholars on the subject and functions of modern general pedagogy.

At present, it should be borne in mind that the educational process is being transformed in accordance with the transformations of civilization. Given that educational institutions and educational institutions operate in market conditions, the study of their competitiveness, management technologies, business processes in education, achieving quality standards of education are becoming increasingly important. At the same time, the study of such problems within the disciplinary boundaries of pedagogy faces significant difficulties that cannot be overcome by applying only the methodology of pedagogy. The same can be attributed to the processes taking place in the economics of education, sociology of education, educational policy and so on. Thus, educational phenomena and processes that reflect the integration of different branches of science in the formation of new knowledge about education, the interaction of education with other spheres of society can be studied only in inter- and multidisciplinary approaches, including educational science.

In recent years, a new scientific direction of integrated research in the field of education education - has been actively developing in the world. Enlightenment recognizes a priori that education in recent years has become radically different and qualitatively different from previous traditional views on it. Education views education broadly, just as (Ito, 2013):

- the process of external assimilation by the individual of generalized social experience and values;

- result, level of general culture and education of people;

-value (state, public, personal);

- social institution that affects the state of consciousness of society;

- socio-cultural phenomenon, the system of various educational institutions and educational institutions.

As you know, the main approaches to scientific research are classified according to the criterion "measure of the completeness of knowledge of the surrounding world."

These approaches include (Lenoir, Larose, Geoffroy, 2000):

1. Disciplinary.

2. Interdisciplinary.

3. Multidisciplinary and transdisciplinary.

Research conducted within a disciplinary approach is research conducted within a single scientific field, limited by its object, subject and research methodology.

The main feature of disciplinary research is that the selected problems are investigated using the methodology and scientific tools of a particular science. The disciplinary approach is applied by specialists in a specific scientific field.

At the same time, solving complex problems of society and a person requires interaction and convergence between various fields of scientific knowledge, disciplines and subdisciplines, and 
therefore require the involvement of representatives of different sciences in research to ensure integrity, comprehensiveness and complexity in solving the problem. multi- and interdisciplinary research in recent years, increasing attention to interdisciplinary research.

Interdisciplinary research is research that involves the interaction of various fields of scientific knowledge in the study of the same object of complex reality. The main features of interdisciplinary research include:

- a combination of different areas of scientific knowledge;

- using the methodology and language of more than one discipline (two);

- analysis and interpretation of the results from the position of the leading discipline.

It should be emphasized that the impetus for the development of interdisciplinary research in the world was the emergence of disciplines and branches of knowledge, in which the level of interdisciplinarity turned out to be much higher than that of others.

The greatest dynamism and interdisciplinary potential is observed in the social and human sciences, for which significant amounts of funding are allocated in developed countries due to sociopolitical and economic reasons, in particular the development of a large-scale market for products and services, recognition of the leading criterion in the system of modern values as the indicator of "quality of life".

Summarizing the achievements of scientists, the following types of interdisciplinarity can be distinguished (Arora, Srinivansen, 2020):

-between scientific branches;

-between separate specialties of the same industry;

- between individual specialties of different fields of science.

Such types of interdisciplinarity are consistent with the classifications of J. Klein and R. Koening. Interdisciplinarity, according to J. Klein, is divided into narrow and broad. We are talking about narrow interdisciplinarity when in the process of research there is an integration of disciplines that are close in methodology and paradigms (for example, separate specialties of the same scientific field). Wide interdisciplinarity implies the integration of methods, concepts and / or theories of sciences that have little compatibility (for example, different scientific branches, separate specialties of different branches of science).

The forms of integration determine the search for points of contact between established branches of scientific knowledge and restructuring - the allocation of parts of disciplines for the formation of a new coherent whole.

As for the types of interdisciplinarity, the most successful for research in the field of education, in our opinion, is the allocation of "soft" and "hard" types of interdisciplinarity, since it is the type of interdisciplinarity that can be considered as a criterion for distinguishing between pedagogical research and research in educational science (educational sciences) ...

Pedagogical research is inherently always distinguished by a mild type of interdisciplinarity, since research of purely pedagogical phenomena and processes requires a narrow interdisciplinarity: in such studies, scientific disciplines that are close in methodology and paradigms are integrated. Research in educational sciences (light studies) can always be attributed to a "rigid" type of interdisciplinarity, since such studies implement a "broad" interdisciplinarity: methods, concepts and / or theories of sciences are used that have little compatibility (philosophy of education, history of education, cultural studies education, education management, educational policy and educational law, economics of education, sociology of education, etc.).

Thus, the research of the modern educational industry cannot be carried out solely on the basis of the methodology of pedagogy. More and more, in the study of the functioning of the sphere of education, educational phenomena and processes, there is a need to involve the methods and cognitive field of other fields of science. 
In addition to the natural development of science itself, US researchers include the following factors affecting the dynamics of interdisciplinary research (Shkabarina, 2020):

- Targeted research programs, the funding of which significantly exceeds the cost of nonspecific fundamental and applied work.

- Institutional support: the issue of interdisciplinarity is discussed at the level of academic science, since the academic sector is a leader in interdisciplinary research, the emergence of new branches of knowledge, etc.

According to the US National Academy of Sciences, the greatest progress in the creation and conduct of multidisciplinary research has been achieved in industrial and specialized government (national laboratories, special institutes, etc.) research structures. Unlike the academic sector, the activities of industry laboratories are mainly aimed at solving applied scientific problems that require interdisciplinary approaches. The focus on practical results ensures a high level of cooperation and collaboration of specialists from different fields of scientific knowledge.

- Constant growth in the level of contacts between industry and academic science: the creation of small and medium high-tech companies in the leading countries of the world by university scientists working for industrial corporations, the encouragement of internships and exchanges of specialists between the academic and industrial sectors of science and industry.

- Educational policies to encourage interdisciplinary and multidisciplinary research.

As for the European Union, interdisciplinary research is mainly supported within the framework of large targeted programs through the creation of specialized centers where personal (and not "virtual") contacts of scientists are implemented, which is important for the formation of inter- and multidisciplinary teams, the exchange of ideas. and methods.

So, when solving problems of generating clean energy, a promising step in stimulating interdisciplinary research is the formation of "horizontal" between institutional links, including international ones, and the creation of joint research programs and structures by higher educational institutions and other research structures.

The integration and globalization processes taking place in the world determine the need to introduce such a system of continuous improvement of lifelong professional training of teachers, which would, on the basis of national heritage and established traditions, be able to form the level of teachers who are able to carry out professional activities on democratic and humanistic principles, to ensure the development and development of self-realization. personality, satisfaction of their spiritual and cultural needs, as well as the need to be competitive in the labor market.

Unfortunately, the existing system of postgraduate pedagogical education is more characterized by a subject-centered structure of the educational process, which complicates the implementation of multivariate educational programs and projects on the problems of pedagogical skills, innovative technologies and interactive forms and methods of teaching. So far, the prevailing approach is where each of the disciplines of advanced training courses is aimed at the formation of its own system of knowledge, skills and abilities. As a result, a variety of knowledge and skills are acquired by listeners discretely, with a break in time and space. The synthesis of knowledge in various academic disciplines is carried out by specialists most often independently on a personal level. This requires a revision of the positions of the course training of working teachers in the system of advanced training, the introduction of an optimal system of integrative content of postgraduate pedagogical education, new constructions of intro-, interdisciplinary knowledge that can significantly affect the improvement of the quality of professional growth of teachers.

As the practice of higher educational institutions of pedagogical education shows, the most optimal quality of personnel training in the advanced training system is achieved by credit-modular and modular accumulative training systems by forming holistic ideas about the content of training students in their entirety, versatility, and multidimensionality in accordance with the educational policy of the state. That is why integration, interdisciplinarity today is the defining trend of the 
pedagogical process of postgraduate pedagogical education, which makes it possible for the educational process to become more saturated and purposeful (in the direction of the intellectual development of the individual).

This approach contains more opportunities for the formation of alternative thinking of listeners, which implies freedom in assessing facts and events, reconciling the contradictions between the fragmentation of the assimilation of knowledge in different disciplines and the need for their synthesis, complex application in professional labor activity. Interdisciplinary relations in the educational process of postgraduate education institutions are characterized by the following functions (Cordeiro, 2021):

1. Educational function. Consists in the fact that interdisciplinary connections contribute to the formation of a system of knowledge about society and nature, an idea of a holistic picture of the world.

2. Educational function. It is expressed in the promotion of interdisciplinary relations in all areas of personality education, the formation of educational culture and literacy, understanding the place and role of subject knowledge in the training system, striving to master new knowledge.

3. Developing function. It is expressed in promoting the formation of cognitive activity, interest in discipline, promoting the development of thinking processes: the ability to carry out analysis and synthesis, to concretize and generalize, to draw an analogy.

4. Didactic function. It is interpreted as a set of means, forms, techniques and methods used in the educational process and aimed at integrating knowledge, skills and abilities.

5. Logical function. It is based on determining the logical structure of knowledge (concepts, facts, phenomena, laws, theories, etc.) for individual academic disciplines, clarifying the mechanism of interaction between these disciplines.

6. Forming function. Promotes the formation of such subject skills, which become the basis for the formation of integrated skills and qualities.

7. Psychological function. Provides the creation of a favorable psychological microclimate, awakening interest in studying the material, positive motivation for learning, enhancing cognitive activity, striving for mastering new knowledge.

\section{CONCLUSION}

Having comprehensively investigated the problem, we can conclude that interdisciplinarity is a modern teaching principle that affects the selection and structure of educational material in a number of disciplines, enhancing the consistency of students' knowledge, activates teaching methods, orients towards the use of complex forms of organizing education, ensuring the unity of educational educational process.

With the help of interdisciplinarity at a new, qualitative level, the tasks of teaching, development and education of students are solved, the foundation is laid for a comprehensive vision, approach and solution of complex problems of reality. That is why the principle of interdisciplinarity is applied in teaching and upbringing of schoolchildren.

Interdisciplinarity contributes to the implementation of the main ideas and methods of pedagogy:

- problematic and heuristic, inductive and deductive approach;

- application of knowledge in practice;

- the materiality of the nature of knowledge and the dialectic nature of research methods.

The implementation of an interdisciplinary synthesis of various academic subjects will make the material being studied easier, more understandable, will help students apply their knowledge and skills in specific situations both in educational and extracurricular activities, in future industrial, scientific and social life. 
The development of modern education requires research that transcends disciplinary boundaries and acquires signs of inter- and multidisciplinarity. A qualitatively new level of such research can be provided on the basis of educational science, methodologically aimed at studying objects and phenomena with a "rigid" type of interdisciplinarity that go beyond the established subject of pedagogy.

The criterion for distinguishing between pedagogical research and research in the field of educational science (educational sciences) can be considered the type of interdisciplinarity of research, respectively "soft" or "hard", which determines a narrow or broad interdisciplinarity. Stimulation of interdisciplinary research in the field of education should take place through educational programs, the creation of various centers and the establishment of inter-institutional contacts, as well as the development of financial policies to support such research, the creation of mechanisms for coordinating and supporting interdisciplinary projects in the field of education at the national and supranational levels. The social sciences, humanities and life sciences will be the leader in interdisciplinary research, according to most forecasts.

Authors' Contributions: Kotyk, T.: conception and design, acquisition of data, analysis and interpretation of data, drafting the article, critical review of important intellectual content; Romanyuk, S.: conception and design, acquisition of data, analysis and interpretation of data, drafting the article, critical review of important intellectual content; Kisil, IF.: conception and design, acquisition of data, analysis and interpretation of data, drafting the article, critical review of important intellectual content. All authors have read and approved the final version of the manuscript.

Ethics Approval: Not applicable.

Acknowledgments: Not applicable.

\section{REFERENCES}

Cordeiro, E. de P. B., Marques, M. M. C., \& Costa, M. T. N. (2021). Socio-emotional education: paths to inspire studies, research and practices. Revista Tempos E Espaços Em Educação, 14(33), e13729.

https://doi.org/10.20952/revtee.v14i33.13729

Shkabarina, M.;et al. (2020) Formation of Future Educators' Professional Training for Introducing Social Experience by Means of Innovative Technologies of Education to Senior Preschoolers.Behavioral Sciences, 10.2, p.42.

Arora, A. K., \& Srinivansen, R. (2020). Impact of pandemic COVID-19 on the teaching-learning process: A study of higher education teachers. Parabandhan: Indian Journal of Management, 13(4), 43-56.

https://doi.org/10.17010/pijom/2020/v13i4/151825

Bansak, C. \& Starr, M. (2021). Covid-19 shocks to education supply: how 200,000 U.S. households dealt with the sudden shift to distance learning. Review of Economics of the Household. https://doi.org/10.1007/s11150-020-09540$\underline{9}$

Suissa, J. (2015). Character education and the disappearance of the political. Ethics and Education,10(1), $105-117$. https://doi.org/10.1080/17449642.2014.998030

Vlieghe, J, Zamojski, P (2020) Redefining education and politics: On the paradoxical relation between two separate spheres. Policy Futures in Education. Epub ahead of print 3 August 2020. https://doi.org/10.1177/1478210320943808

Yuk, Fai Leung. (2003, January). The Essence of Interdisciplinary Research - Mindset Matters.

ScienceCareers. Retrieved from

http://sciencecareers.sciencemag.org/career magazine/previous issues/articles/2003 01 31/noDOI.1798909550341 $\underline{9373115}$

Florian, L., \& Black-Hawkins, K. (2011). Exploring inclusive pedagogy. British Educational Research Journal, 37(5), P. 813-828. https://doi.org/10.1080/01411926.2010.501096

Ito, J. P. (2013). Hypermetrical schemas, metrical orientation, and cognitive-linguistic paradigms. Journal of Music Theory, 57(1), 47-85. https://doi.org/10.1215/00222909-2017106 
Phoenix, C., Osborne, N. J., Redshaw, C., Moran, R., Stahl-Timmins, W., Depledge, M. H., ... \& Wheeler, B. W. (2013). Paradigmatic approaches to studying environment and human health:(Forgotten) implications for interdisciplinary research. Environmental Science \& Policy, 25, 218-228. http://doi.org/10.1016/i.envsci.2012.10.015

Rana, M. (2017). Disability in Children's Literature. Tropes, Trends and Themes. Interjuli. Internationale Kinder- und Jugendliteraturforschung. https://doi.org/10.5167/uzh-75903

Úcar, X. (2013). Exploring different perspectives of Social Pedagogy: towards a complex and integrated approach. Education Policy Analysis Archives, 21(36), 1-19. https://doi.org/10.14507/epaa.v21n36.2013

Klein, Julie T. (2002) Interdisciplinary Education in K-12 and College - A Foundation for K-16 Dialogue. New York.

Lenoir, Y., Larose, F., Geoffroy, Y. (2000) Interdisciplinary Practices in Primary Education in Quebec - Results from Ten Years of Research. In: Issues in Integrative Studies, Vol. 18, 89-114.

Smelser, Neil J. (2004) Interdisciplinarity in Theory and Practice. In: Camic, Charles; Joas, Hans, eds. The Dialogical Turn - New Roles for Sociology in the Postdisciplinary Age. Lanham, MD, 43-64.

Received: 31 October 2022 | Accepted: 11 December 2022 | Published: 14 January 2022

This is an Open Access article distributed under the terms of the Creative Commons Attribution License, which permits unrestricted use, distribution, and reproduction in any medium, provided the original work is properly cited. 